Under our experimental conditions, the $\mathrm{CO}$ diet reduced net oleate oxidation in calf liver. Liver accumulation of TG, previously observed in vivo in the $\mathrm{CO}$ diet, could be partly explained by an increase of fatty acid esterification in response to the reduction of the oxidative pathway.

\section{OTHER METABOLISMS}

Effects of dietary coconut oil on the density distribution and the chemical composition of plasma lipoproteins in the preruminant calf. $D$. Durand, D. Bauchart, C. Picherit, D. Gruffat, B. Graulet (Inra, LCMH, Theix, 63122 StGenès-Champanelle, France.

Soybean oil added to milk replacers for preruminant calves induced hypercholesterolemia by specifically increasing the plasma concentration of high density lipoproteins (HDL). In contrast, the metabolic effects of coconut oil, rich in medium-chain fatty acids (MCFA, C8C14: $64.9 \%$ of total fatty acids) and presently recommended for high growth performances, are still unknown. Therefore, two groups of seven $\mathrm{H} \times \mathrm{F}$ male calves, aged $15 \mathrm{~d}$, were given a basal milk replacer as the sole diet containing beef tallow (T) or coconut oil (CO) for 19 days. At the end of the experiment, blood samples were collected during the lipid postabsorptive period. Plasma lipoproteins were separated by sequential ultracentrifugal flotation or by density gradient ultracentrifugation. Compositions of their lipids and fatty acids were determined by enzymatic methods and by gas-liquid chromatography, respectively. Plasma contents of apolipoproteins B and A-I were determined by radial immunodiffusion. Compared with the $\mathrm{T}$ diet, the $\mathrm{CO}$ diet increased plasma-free cholesterol (30 versus $14 \mathrm{mg} / \mathrm{dL}, P<0.05$ ), cholesteryl esters
(CE) (258 versus $127 \mathrm{mg} / \mathrm{dL}, P<0.01$ ), and apo A-I (129 versus $87 \mathrm{mg} / \mathrm{dL}, P<$ 0.01 ) because of specific increases in light HDL (density 1.060 to $1.091 \mathrm{~g} / \mathrm{mL} ; 285$ versus $131 \mathrm{mg} / \mathrm{dL}, P<0.01)$ and very light (type 1) HDL (density 1.026 to $1.091 \mathrm{~g} / \mathrm{mL} ; 65$ versus $8 \mathrm{mg} / \mathrm{dL}, P<0.01$ ). MCFA provided by the $\mathrm{CO}$ diet were transported in triglycerides of chylomicrons (density $<0.950 \mathrm{~g} / \mathrm{mL} ; 23.6 \%$ of total MCFA) and of very low density lipoproteins (density 0.950 to $1.006 \mathrm{~g} / \mathrm{mL}$; $15.0 \%$ ) and mainly in CE of HDL $(44.1 \%)$. Plasma accumulation of light HDL rich in cholesterol in calves given the $\mathrm{CO}$ diet can be explained by 1) a higher rate of cholesterol synthesis in hepatocytes resulting from the conversion of MCFA into acetyl CoA, 2) a higher efflux of cholesterol from tissues into plasma, subsequently incorporated in HDL as CE via the lecithin:cholesterol acyltransferase reaction, and 3) a limited uptake of HDL particles by the liver and the steroidogenic tissues.

Comparison of two saturated fatty acid intakes with steady intakes in unsaturated fatty acids on plasma lipids and fatty acids in a monk collectivity study. H. Dabadie ${ }^{a, c}$, E. Peuchant ${ }^{b}$, M.C. Delmas-Beauvieux $^{b}$, A. Cazanave ${ }^{a}, M$. Bernard $^{a}$, V. Rigalleauc, H. Gin ${ }^{c}$, F. Mendy ${ }^{a}$, M. Clerc ${ }^{b}$, J. Paccalin ${ }^{a}$ ('Laboratoire de thérapeutique, baboratoire de biochimie, Université Victor Ségalen Bordeaux 2; 'Service de nutrition, Hôpital Haut-Lévêque, 33600 Pessac, France).

If oleate, linoleate and linolenate intakes are actually defined, recommended saturated fatty acid (SFA) intakes are not well known. The aim of our study was to clarify the most beneficial rate in SFA.

Twenty-five male monks without dyslipidemia (mean age: 61 years, weight: $72 \mathrm{~kg}$, and BMI: 25 ) were provided two isocaloric (2 $200 \mathrm{kcal}$ ) diets for 5 weeks 